\title{
Modification of the Norwegian Traffic Light States as the Method to Reduce the Travel Delay
}

\author{
Setiyo Daru Cahyono ${ }^{1, *}$, Sutomo ${ }^{2}$, Seno Aji ${ }^{1}$, Sudarno $^{2}$, Pradityo Utomo ${ }^{2}$, Tomi Tristono ${ }^{2}$ \\ ${ }^{1}$ Department of Civil Engineering, Merdeka Madiun University, Indonesia \\ ${ }^{2}$ Department of Mechanical Engineering, Merdeka Madiun University, Indonesia
}

Copyright $\bigcirc 2019$ by authors, all rights reserved. Authors agree that this article remains permanently open access under the terms of the Creative Commons Attribution License 4.0 International License

\begin{abstract}
Traffic lights have a vital role as regulatory systems to control the vehicles flowed in urban networks. This research is based on the real case. The traffic lights are installed at a massive intersection of an urban network consisting of four sections. The systems control implements the modification of the Norwegian traffic lights states. The behavior of traffic lights states were modeled using Petri net method. For the model verification and validation, the invariants and simulation were applied. The purpose of the implementation of this control system was to reduce travel delays. The intersection performance level was good while the average travel delay on all sections was low. The method used for the testing was the comparison of the simulation results due to the settings that apply the standard system to the imitation of the reality of the system using modifications of the Norwegian traffic lights states. The control system was able to reduce the travel delays slightly. The average of Level of Service (LoS) index of the roads for all sections was at level D. It improved the performance of the intersection, but not yet significant. In addition to setting traffic lights, the presence of flyovers is urgent to improve travel delays.
\end{abstract}

Keywords Petri Net, Travel Delays, Modification of the Norwegian Traffic Lights States, Level of Service (LoS) Index

\section{Introduction}

Generally, one of the traffic lights functions is to separate the different vehicle traffic flows and prevent the conflicts [1]. Its implementation offers the safety of travel and efficiency [1]. But on the contrary, its improper use will lead to heavy congestion, inefficient travel, inconvenience, and high travel delays [2].

This research is done in connection with an intersection that has massive size. It consits of four sections with the horizontal geometric grade. It is the left-hand vehicle traffic.
For reducing the travel delay, the traffic lights states apply the modification of the Norwegian traffic lights states. This paper investigates its significance when compared to a standard system. As we all know, travel delay is an indicator of the performance of the vehicle traffic passing on the road network [3].

The intersection is the gateway from the northern city of Madiun - Indonesia. Its scheduling of the traffic light applies a fixed time strategy. Due to the massive size, the intersection requires a relatively long time interval to clear the intersection of the vehicle traffic flow. It is done when all red signal. Its purpose is to ensure that no conflict occurs [3].

Whether traffic lights of the modification of Norwegian traffic lights are an efficient method to reduce travel delays? This method is desirable to achieve the aim for improving the performance of the intersection as the challenge of this research.

Commonly, the standard traffic lights have three states [4]. The states of Norwegian traffic lights are green, yellow, red, yellow-red both light up simultaneously and turn to green again become a traffic light cycle [5], [6]. The modification of the Norwegian traffic lights has four states too. They are green, the first yellow, red, the second yellow, and return to the green signal again as the initial state.

In this paper, the traffic lights behavior was modeled by Discrete Event Systems (DES). The system can formulate the sequences of events occurring at the set time intervals [7]. One of DES's manifestations is Petri Net [7]. It can be a sequence of events design on traffic lights [8]. Petri net model can also be attached with time (TPPN / Time Place Petri Net) [8]. The model system can offer representations of conflict situations from various resources, synchronization of events or schedules, and multiple constraints that should be prioritized [9], [10].

Many previous researchers have done the study on the dynamics of system behavior using Petri net. Y. S. Huang, et al. [1], studied the intelligent transportation systems. It is the modular design of urban traffic-lights control. The systems are based on the synchronized timed petri nets. D. 
Adzkiya [7] built the model of the behavior of traffic lights and the simulations using Petri nets. M. Dotoli M. and M. P. Fanti [11] reviewed the model of urban traffic network through Petri net with time and color.

In the following is the research about travel delays. $\mathrm{R}$. Kurniawan and R. A. Al-Hasibi [2], with their research entitled the concept of adaptive traffic control. It is synchronized to the road density to minimize the duration of the waiting time. M.B. Asih and I. Muthohar [12] suggested removing activity and obstacles such as vehicles parking on the roadside. While roadside activity was high, road capacity became low. Therefore, the travel delay became high due to the high saturation level of the road. Congestion can reduce traffic comfort, safety, travel speeds of road users, and add travel delay as well as raising the vehicle operating costs. A. Narendra and A. Budiwirawan [13] studied a method for reducing travel delays by building a mid-way block and traffic signs. The results seem insignificant when applied to an intersection in the city of Semarang. F. Kurniawan, et al., [14] developed the systems that can modify the green time interval of each section of the intersection based on the traffic volume. The appropriate green time interval time of the traffic light can improve the performance of the intersection. Papageorgiou et al., [15] reviewed the road traffic control strategies. The study of T. Tristono [16] about the traffic vehicles delay on a signalized intersection. It was integrated into the railway doorstop.

\section{Research Methods}

This research uses Petri net with Place-Time for the modeling method of the behavior of traffic lights. Each state of the traffic light is equipped with the time interval or duration. The traffic lights design the models settings for the traffic of a massive intersection at Madiun city. The traffic lights apply the modification of the Norwegian traffic lights states for the reduction method of the travel delays.

\subsection{Basic Petri Net, Its Properties, and P-Time Petri Net}

A Petri Net is a graph installed in its directions and weights. The 4-pair of elements of the basic/ classical Petri net are places, transitions, arcs, and tokens [9]. Places for presenting the events/ states. Transitions have a function for firing, which is to change events/ states. Place is presented with circle/ ellipse and transition by box/ square. The formal definition of the Petri net structure [10] is written below.

Definition 1. A Petri net structure $N=$ (P, T, Pre, Post).

It consists of 4-pairs elements. $\mathrm{P}$ and $\mathrm{T}$ are sets of the finite elements of places and transitions, respectively. $\mathrm{P}=$ $\{\mathrm{p} 1, \mathrm{p} 2, \mathrm{p} 3, \ldots \mathrm{pn}\}, \mathrm{T}=\{\mathrm{t} 1, \mathrm{t} 2, \mathrm{t} 3, \ldots \mathrm{tm}\}$. Pre: $(\mathrm{PxT}) \rightarrow$
$\mathrm{N}+$ is the input function that defined by the directed arch from place to transition. Post: (TxP) $\rightarrow \mathrm{N}+$ is the output function that defined by the directed arch from the transition to the place which $\mathrm{N}+$ is a non-negative integer.

Definition 2. A basic Petri net is $\mathrm{PN}=(\mathrm{N}, \mathrm{Mo}) . \mathrm{N}$ is a Petri net, and Mo is its initial value.

The dynamic behavior of a Petri net is represented by the marking path from Mo to Mz. The marking sequence is declared with firing the enable transitions. The transition $t$ $\in \mathrm{T}$ is said to be enabled while all input places $\mathrm{p} \in \mathrm{P}$ have at least the number of tokens equal to the weight of the arc connecting places $p$ to transition $t,(M(p) \geq \operatorname{Pre}(p, t) ; p \in P)$.

Several desired functional properties are used for verification and validation Petri net states. This proves that the design of an absolute model is correct. Several of the main properties of Petri Net are, i.e., reachability, reversibility, boundedness, safeness, and liveness [9], [10]. Firing of transitions resulting in a possible marking sequence accomplished with a change of token distribution. The marking of $\mathrm{Mz}$ is said to be reachable from Mo if there is a fire sequence that builds a path from Mo to Mz. This is stated by $M z \in \mathrm{R}(\mathrm{N}, M o)$. The Petri net design is reversible when it is possible to return to the original state. A Petri net (N, Mo) is k-bounded if the number of tokens in each place will not exceed $\mathrm{k}$ for any marking that can be reached from Mo, which $\mathrm{k}$ is positive integers. Petri net $(\mathrm{N}, \mathrm{Mo})$ is safe while it is 1-bounded [10]. Petri net (N, Mo) is live for every $\mathrm{Mz}$ that can be reached from Mo. The liveness on a Petri net is a guarantee that has no deadlocks [10].

Events that are modeled on the states of Petri net can have an interval time interval by adding the duration of the event to each place [8].

Definition 3. A P-Time Petri net is a pair (PN; Ip). PN is a Petri net with the initial state, and Ip is the time function defined as Ip : P $\rightarrow(\mathbb{Q}+\bigcup 0) \times(\mathbb{Q}+\bigcup \infty)$.

The time interval $\mathrm{Ip}=[\boldsymbol{\alpha}, \beta]$ connecting with $0 \leq \boldsymbol{\alpha} \leq \beta$. It is the static time interval to express the duration while a token in a place $\mathrm{P}$ is available for firing by a transition. Before $\boldsymbol{\alpha}$ and after $\beta$, the existence of a token is nonavailable or it namely as a dead token. The value $\boldsymbol{\alpha}$ is the minimum date, and $\beta$ is the maximum date. A fixed time interval of a signal of the traffic lights has occurred while the minimum date is equal to the maximum date.

\subsection{Petri Net Traffic Lights Model}

This is the four-phases of Petri net traffic lights model of an intersection. It implements modifications of the Norwegian traffic lights system. The standard traffic signals are lit up with a fixed sequence as a loop cycle. In general, traffic signals are green, yellow, and red [4]. In traffic signaling with the Norwegian system, it has one more stage, which is a red-yellow signal that simultaneously lights up in the traffic signaling with modifications of the Norwegian system turning the fourth 
stage into yellow color only. It happens after the red signal ends. The proper application of the yellow signal method has been proven to reduce travel delays [4].

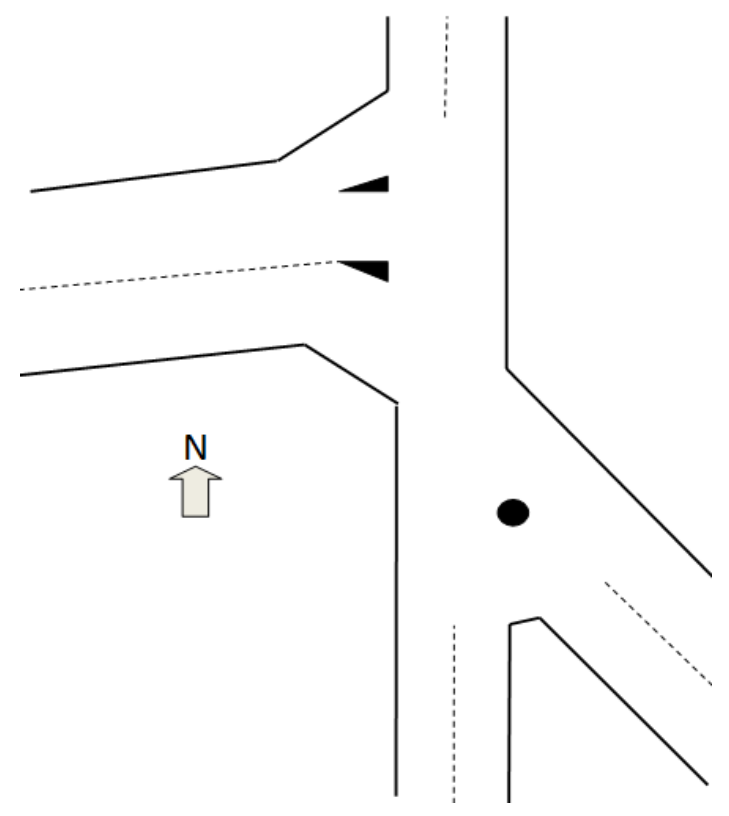

Figure 1. The signalized intersection that consists of four sections. It attached mid-way block border. The traffic flow of all section moves in two directions, entering and away of the intersection. The distance of the stop line of the southern section to the northern section is about 100 meters The eastern section is not perpendicular to the intersection, and it is not precisely in front of the western section. The flow of northern and western sections is allowed to Turn Left On Red (LTOR).

The red-yellow method or yellow signals after the red signal informs the driver that the red traffic signal will end soon. The drivers are allowed to start the movement of the vehicle soon. Typically, this method is applied to signaling at an intersection that does not use a seven-segment board to present the remaining red signal time intervals. In this case, the signalized intersection has applied modifications of the Norwegian system. Therefore, there is no sevensegment board.

\subsubsection{Invariants}

Traffic control signals must have the error-free of the features, no deadlocks, no scheduling for conflicting vehicle movements, can serve all phases, and should be able to return to initial state [7]. Petri net model verification and validation applies invariants and simulations as the event graphs. The invariant formula presents the marking of the place of Petri net model. It is " 1 " or " 0 " only, those mean turn on or off, respectively. Place controls are not included in the invariants.

$$
M(G i)+M(Y i)+M(R i)=1
$$

Invariant (1) states that there is only one token in one of three places $G i$ (Green), $Y i$ (yellow), and $R i$ (Red), $i=1,2,3,4$.

Invariant (2) indicates no conflicting vehicle movements. When there is a token in place $R i$, there must be a token in one of the three places $G j, Y j$, or $R j$ while $i, j=1,2,3,4$ and $i$ $\neq j$.

$$
\begin{aligned}
& \mathrm{M}(\mathrm{Gi})+\mathrm{M}(\mathrm{Yi})+\mathrm{M}(\mathrm{Ri})=\mathrm{M}(\mathrm{Rj}) \\
& \text { while } \mathrm{M}(\mathrm{Rj})=1
\end{aligned}
$$

Invariant (3) is attached with an intermediation place $S$ that represents for all red signals.

$$
\sum_{i=1}^{4}\{M(G i)+M(Y i)\}+M(S)=1
$$

\subsubsection{Traffic Lights Schedule}

The traffic light simulation illustrates the scheduling of each signal in all phases with the timing of the events.

In Table 1. is the traffic light schedule for each phase. The high vehicle volumes at sections 2 and 3 are served using the longer green intervals of time than others. All red signals for all sections are six seconds. For a small intersection, all red signals are three seconds. The long intervals of all red signals have the potential to increase travel delays significantly. When the number of phases is smaller than four, this also has implications for travel delays. However, this can be a cause of conflict in the movement of vehicle flow.

Table 1. The Time Schedule of Four Phases of Standard Traffic Signals

\begin{tabular}{|c|c|c|c|c|c|}
\hline \multirow{2}{*}{ Phases } & \multirow{2}{*}{ Green } & \multicolumn{2}{|c|}{ Inter Green } & \multirow{2}{*}{ Red } & \multirow{2}{*}{ Cycle } \\
\cline { 2 - 5 } & & Yellow & All red & & \\
\cline { 2 - 5 } & \multicolumn{5}{|c|}{ Seconds } \\
\hline South & 21 & 3 & 6 & 102 & 126 \\
\hline North & 24 & 3 & 6 & 99 & 126 \\
\hline East & 24 & 3 & 6 & 99 & 126 \\
\hline West & 21 & 3 & 6 & 102 & 126 \\
\hline
\end{tabular}




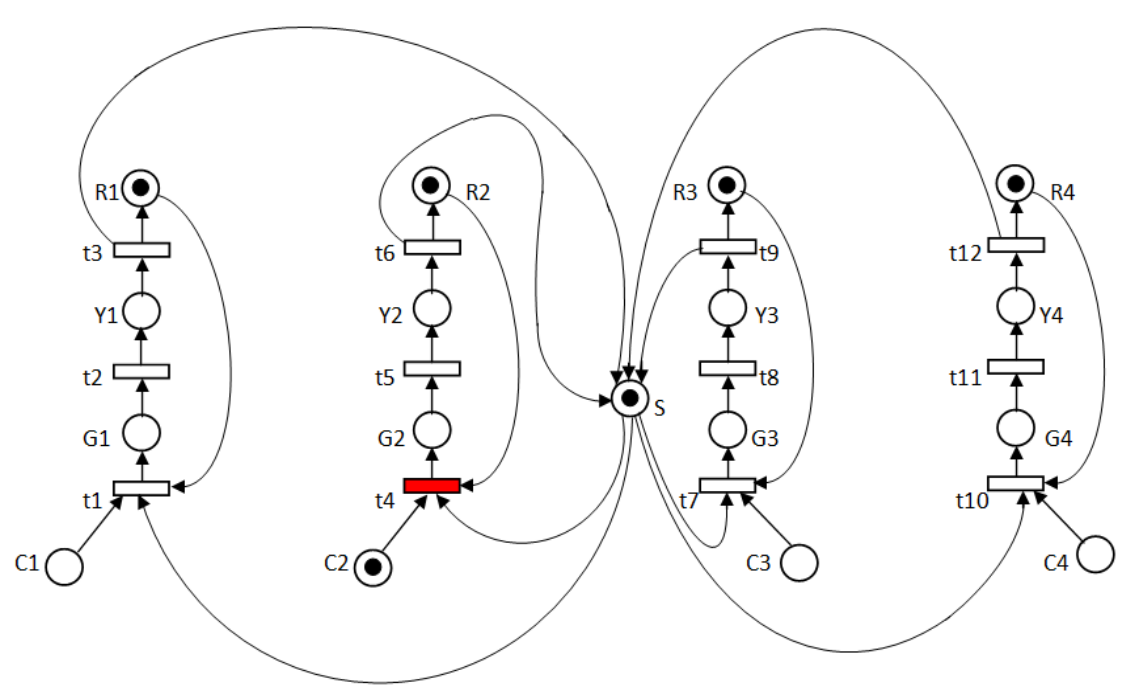

Figure 2. the Petri net model of the traffic light with four phases. It implements the standard traffic signal. Phase 1 consists of signal places G1 (Green_1), Y1 (Yellow_1), R1 (Red_1), and C1 (Control_1). It is similar in phase 2, phase 3, and phase 4. The place S is the intermediation place to construct the phases. Places controls get information from sensors to build the fixed order of the traffic light sections. This traffic light applies the fixed time strategy using predefined time intervals. Transition $t 4$ is enabled and ready to fire due to the information is found in place $\mathrm{C} 2$. While a token exists in place $\mathrm{S}$, all signals are red. This is the time interval to clear the intersection of several remaining traffic flows.

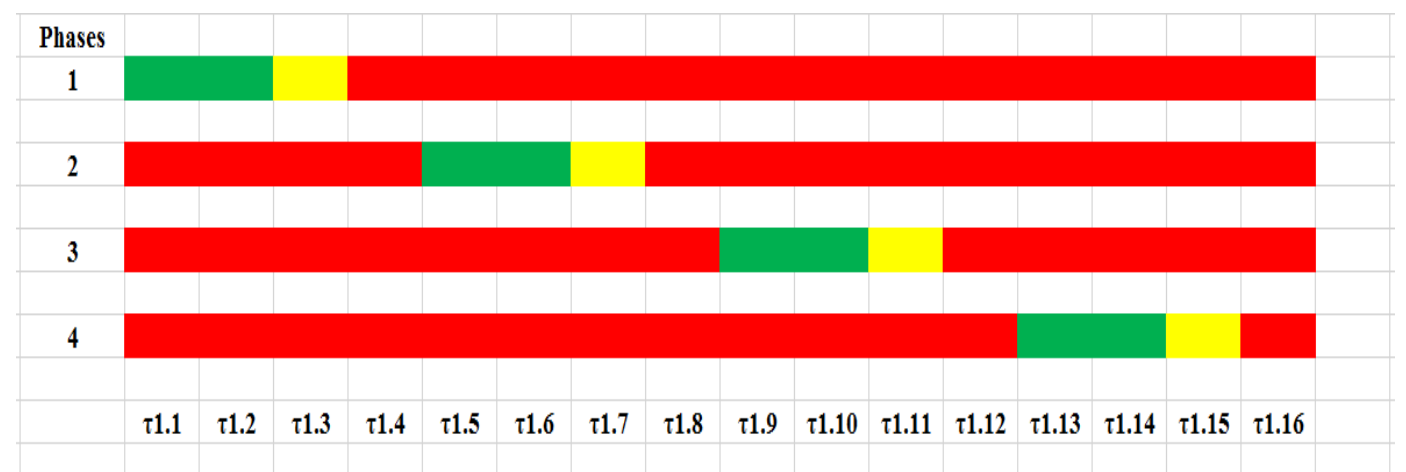

Figure 3. The traffic light simulation results of the standard system those have four phases. When the green signal, a token is in places G1, G2, G3 or $\mathrm{G} 4$ while the time interval $\tau 1.1+\tau 1.2, \tau 1.5+\tau 1.6, \tau 1.9+\tau 1.10$, or $\tau 1.13+\tau 1.14$, respectively. For the yellow signal, the places Y1, Y2, Y3, or Y4 load a token when the time interval $\tau 1.3, \tau 1.7, \tau 1.11$, or $\tau 1.15$, respectively. A token presence in a place $\mathrm{S}$ when all signals are red at time interval $\tau 1.4, \tau 1.8$, $\tau 1.12$, or $\tau 1.16$. The time interval of the red signal at each phase depends on the interval time of the green, yellow signal of all phases, and all red signals. The place controls/ sensors are not attached to the simulation.

\subsection{Travel Delays}

The control of the vehicles stream of an intersection uses traffic signals resulting in the waiting time for vehicles arriving at the time $t_{d}$. It is $\omega\left(t_{d}\right)$ [2].

$$
\omega\left(t_{d}\right)=d\left(t_{d}\right) \times\left(t_{o}-t_{d}\right)
$$

Which, the density $d\left(t_{d}\right)=$ traffic volume, while the time $t_{d} . t_{o}$ is the vehicles departure time. $t_{d}$ is the time when the vehicle arrives at the intersection.

The Eq. (5) is the total waiting time for all vehicles arriving while the red signals turn on. It is $\hat{\omega}\left(t_{o}\right) . d(t)$ is the traffic volume when the time $t$.

$$
\hat{\omega}\left(t_{o}\right)=\sum_{t=t_{o}-T}^{t_{o}-1} d(t) \times\left(t_{o}-t\right)
$$

Table 2. Road Level of Service (LoS) Index

\begin{tabular}{|c|c|}
\hline Service Level Index & $\begin{array}{c}\text { Delay } \\
\text { (Seconds/ PCU) }\end{array}$ \\
\hline A & $\leq 5,0$ \\
\hline B & $5,1-15,0$ \\
\hline C & $15,1-25,0$ \\
\hline D & $25,1-40,0$ \\
\hline E & $40,1-60,0$ \\
\hline F & $\geq 60,1$ \\
\hline
\end{tabular}

Cited from [3] 


\subsection{Modification of the Norwegian Traffic Lights States}

The traffic signals always lit up in a sequence of the state as a loop cycle. The standard road signs feature usually change from green as the initial state, yellow, red and return to green signal [4]. The green signal of standard traffic signal means that the drivers could start driving. The yellow signal indicates that the drivers ready to stop because the signals will turn red immediately. The red signal gives the information that the drivers must stop [4].

The Norwegian traffic signals have one additional stage, i.e., red-yellow that active simultaneously. This stage suggests the driver to get ready start driving. By using this method, hopefully, it can reduce the time delay of traveling of vehicles queue although it does not use seven-segment as countdown timers for presenting the time stop remaining [4]. The modification of the Norwegian traffic lights changes the red-yellow stage into a signal yellow color only after the red signal passed.

\section{Results and Discussion}

While the peak hours, the vehicle arrival volume of the southern section is about 1,200 PCU/ hour and other sections each volume is about 2,000 PCU/ hour. Except for the southern sections, the traffic of vehicles are dominated by heavy vehicles such as intercity buses, dump trucks, trailer trucks. About $45 \%$ and $25 \%$ of vehicles from the north and west sections do the LTOR (Left Turn On Red), respectively. It means their travel delay is zero.

The PCU (Passenger Car Unit) is a vehicle measurement standard metric passing by on the road by comparing them to a single passenger car [3], [4]. The vehicles are categorized into Low Vehicle (LV) is 1 PCU, Heavy
Vehicle (HV) is 1.3 - 3 PCU, Motorcycle (MC) is 0.4, and non-motorized vehicles are ignored.

\subsection{While Implements Modification of Norwegian Traffic Lights States and Its Delay Analysis}

After the red signal ended, the driver's response to start rerunning their vehicles. On the signaling system using Norwegian system or its modification, the response was relatively the same. They moved forward two seconds faster than those applying standard system signaling.

The intersection has a massive size and long distance between the stop line of the sections. It was the reason for the implementation of the modifications of Norwegian signaling system. The signaling uses modifications of the Norwegian system at small intersections have a high risk. Without the disciplinary behavior of drivers to comply with traffic signs, it may create new threats to the safety of travel.

Based on the existing data, it was simulated travel delays with signaling using both systems, i.e., standard system and modification signaling Norwegian system. Both results were compared.

Based on Table 3, the modification of the Norwegian traffic signal applied three seconds for the yellow time interval after the green state and two seconds to yellow after the red signal passed. The time interval for all red signals using four seconds.

Based on Fig. 6, the black line pattern is the vehicle travel delay at the intersection that implemented standard system traffic signals. On the contrary, the red line pattern is a vehicle travel delay at the intersection using the modification of Norwegian system traffic signals. Total travel delay is the multiplication between the amount and the delay of each vehicle. The horizontal axis is the time in a cycle of the traffic signals.

Table 3. The Schedule of Four Phases of Modification of Norwegian Traffic Lights Signals

\begin{tabular}{|c|c|c|c|c|c|c|}
\hline \multirow{3}{*}{ Phases } & \multirow{2}{*}{ Green } & \multicolumn{3}{|c|}{ Inter Green } & \multirow{2}{*}{ Red } & \multirow{2}{*}{ Cycle } \\
\hline & & Yellow1 & Yellow2 & All red & & \\
\hline & \multicolumn{6}{|c|}{ Seconds } \\
\hline South & 21 & 3 & 2 & 4 & 100 & 126 \\
\hline North & 24 & 3 & 2 & 4 & 97 & 126 \\
\hline East & 24 & 3 & 2 & 4 & 97 & 126 \\
\hline West & 21 & 3 & 2 & 4 & 100 & 126 \\
\hline
\end{tabular}




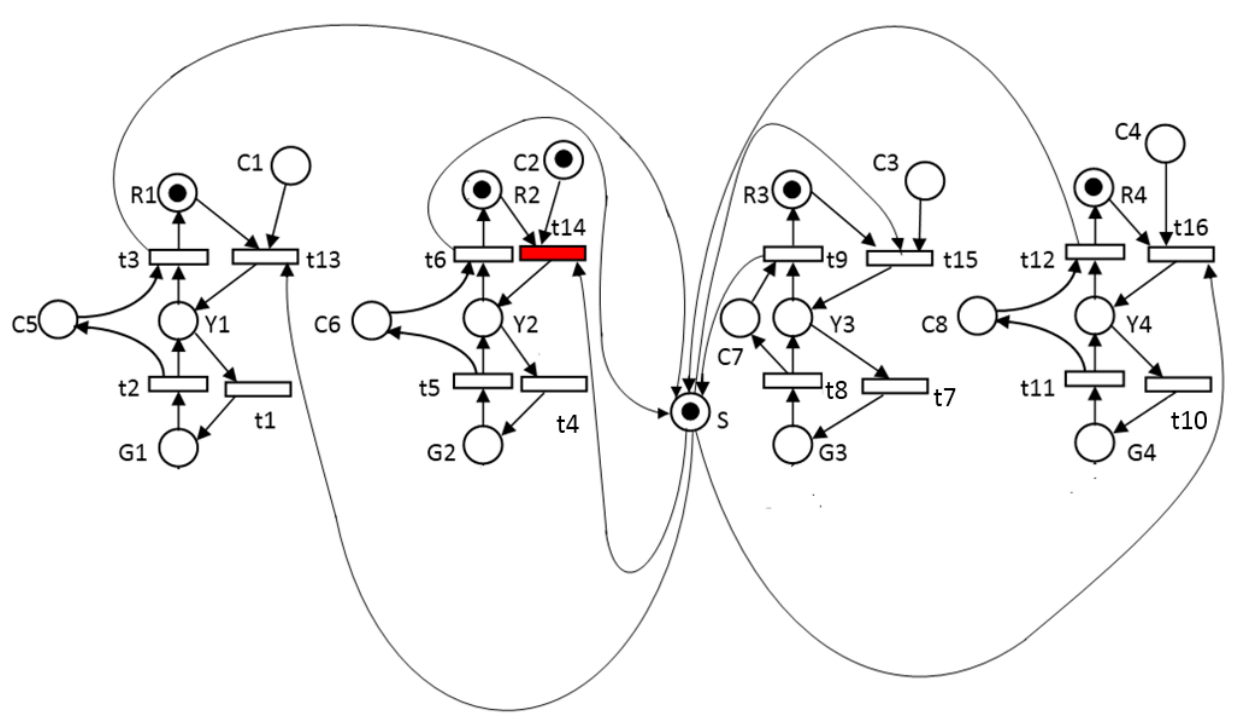

Figure 4. A Petri net model of the traffic light with four phases. It applied the modification of Norwegian traffic signal. Phase 1 consisted of signal places were G1 (Green_1), Y1 (Yellow_1), R1 (Red_1), C1 (Control_1), and C5 (Control_5). Place controls C1, C2, C3, and C4 got information from sensors. Place C5, C6, C7, and C8 control signals of Y1, Y2, Y3, and Y4. It occurred after the green signal. It would turn into a red signal of phase 1, phase 2, phase3, and phase 4, respectively. The others were similar to the model Petri net traffic light with four phases that implemented the standard traffic signal in Figure 2.

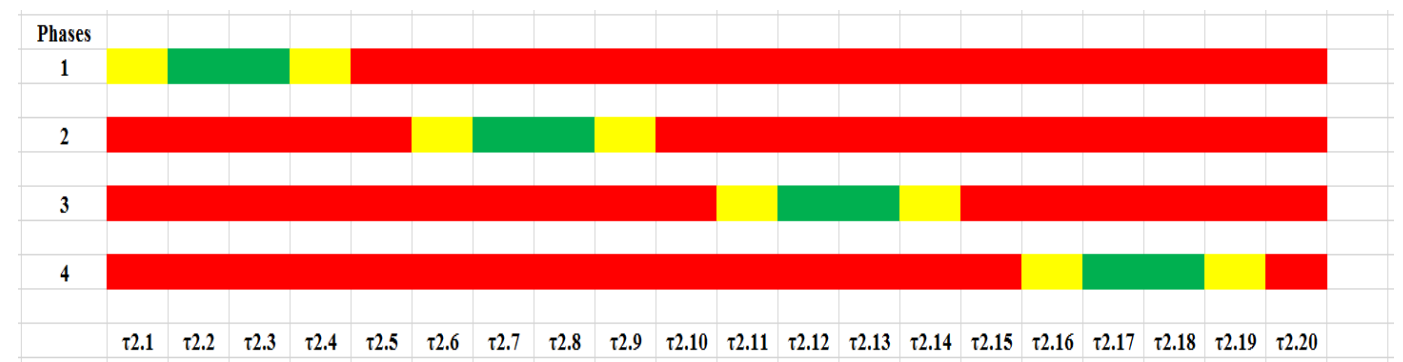

Figure 5. The traffic light simulation results of the standard system those had four phases. When the green signal, a token was in places G1, G2, G3 or G4 while the time interval $\tau 2.2+\tau 2.3, \tau 2.7+\tau 2.8, \tau 2.12+\tau 2.13$, or $\tau 2.17+\tau 2.18$, respectively. For the Yellow1 and yellow2 signals, the places Y1, Y2, Y3, or Y4 loaded a token when the time interval $\tau 2.1$ and $\tau 2.4, \tau 2.6$ and $\tau 2.9, \tau 2.11$ and $\tau 2.14$, or $\tau 2.16$ and $\tau 2.19$, respectively. The Yellow1 represented signal after green state and the yellow2 indicated signal after red state. A token was present in place $\mathrm{S}$ when all signals were red at time interval $\tau 2.5, \tau 2.10, \tau 2.15$, or $\tau 2.20$, which the time interval of $\tau 2.5=\tau 2.10=\tau 2.15=\tau 2.20$. The time interval of the red signal at each phase depended on the interval time of green, yellow1 and yellow2 signal of all phases, and all red signals. The place controls were not attached to the simulation

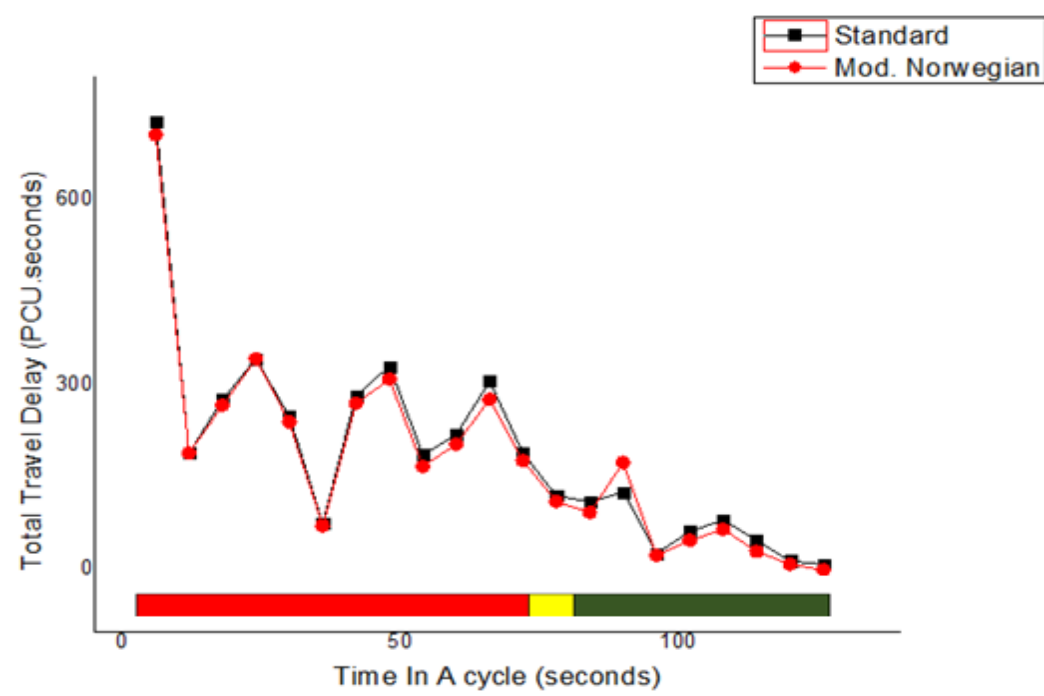

Figure 6. The pattern of total travel delay of all vehicle on a cycle of the traffic lights for126 seconds. This was in the eastern section, which the vehicles were not allowed to Left Turn On Red (LTOR). It implemented four phases of traffic lights signals 
On the left side is the pattern of the total travel delay when the traffic signal start to turn on red. It is the first queuing vehicle that has a high-value travel delay. It shall wait for the longest time interval. On the right side is the pattern of the total travel delay when the traffic signal activated the green signal. At that time, the vehicles gradually leave the intersection. For the Vehicles that arrive at the intersection when the green traffic signal lit, they have a travel delay close to zero.

The assumption, traffic flow has not been saturated. In general, Travel delay patterned with black lines is higher than the red line pattern, but not significant. The pattern decreases with the trend of the transverse wave model. This relates to a computer simulation which assumes that the vehicle's arrival model has a normal distribution. The arrival of the vehicle is measured in every three seconds based on the vehicle sensor request. The highest frequency is the arrival of vehicles which numbers are close to the average. The number of arrivals of large or small vehicles, both have low frequencies.

Refer to Table 4., the average travel delay for all sections that implement the standard signal system is 38.60 seconds/ PCU and for the intersection that applied the modification of Norwegian traffic signal is 36.15 seconds/ PCU. Both Level of Service (LoS) index were D.

Based on Table 4, Generally, the modification of the
Norwegian traffic signal has the smaller average travel delay than the standard system. The differences are not significant and not able to improve the level of service (LoS) index. The LoS score is better in the section that allows the vehicle to turn left even though the traffic signal is red (LTOR). The long time interval of all red signals is an aspect that can cause the travel delay to be high. While a standard traffic signals system, all red takes six seconds and four seconds when applying the modification of Norwegian traffic signal.

For the small intersection, the all red time interval of three seconds can be used. The table is not presented. The average travel delay for all the sections that implements the standard signal system is 33.78 seconds/ PCU and for the intersection that applied full of the Norwegian traffic signal is 31.18 seconds/ PCU. Both Level of Service (LoS) index is $\mathrm{D}$. Based on safety reasons. This cannot be derived due to the massive size of the intersection.

It is while the intersection implements three phases of traffic signals without a schedule for the southern section. The average travel delay for all sections that implements the standard signal system is 34.83 seconds/ PCU and for the intersection that applies the modification of Norwegian traffic signal is 32.54 seconds/ PCU. Both Level of Service $(\mathrm{LoS})$ index is D.

Table 4. The Travel Delay of The Intersection that Implemented Four Phases of Traffic Signals

\begin{tabular}{|c|c|c|c|c|c|c|}
\hline \multirow{2}{*}{ Section } & \multirow{2}{*}{$\begin{array}{c}\text { Volume } \\
\text { (PCU/hour) }\end{array}$} & \multirow{2}{*}{$\begin{array}{c}\text { LTOR } \\
(\%)\end{array}$} & \multicolumn{2}{|c|}{ Average of Delay } & \multicolumn{2}{c|}{ Level of Service (LoS) } \\
\cline { 3 - 6 } & & & \multicolumn{2}{|c|}{$\begin{array}{c}\text { Mod of } \\
\text { Norwegian }\end{array}$} & \multirow{2}{*}{$\begin{array}{c}\text { Standard } \\
\text { Mod of } \\
\text { Norwegian }\end{array}$} \\
\cline { 3 - 6 } & & - & 51.29 & 49.21 & E & E \\
\hline South & 1,200 & 45 & 24.25 & 23.15 & C & C \\
\hline North & 2,400 & - & 52.30 & 48.87 & E & E \\
\hline East & 2,160 & 25 & 33.88 & 30.68 & D & D \\
\hline
\end{tabular}

Table 5. The Travel Delay of The Intersection that Implemented Three Phases of Traffic Signals

\begin{tabular}{|c|c|c|c|c|c|c|}
\hline \multirow{3}{*}{ Section } & \multirow{3}{*}{$\begin{array}{c}\text { Volume } \\
\text { (PCU/ hour) }\end{array}$} & \multirow{3}{*}{$\begin{array}{c}\text { LTOR } \\
(\%)\end{array}$} & \multicolumn{2}{|c|}{ Average of Delay } & \multicolumn{2}{|c|}{ Level of Service (LoS) } \\
\hline & & & Standard & $\begin{array}{c}\text { Mod of } \\
\text { Norwegian }\end{array}$ & \multirow{2}{*}{ Standard } & \multirow{2}{*}{$\begin{array}{c}\text { Mod of } \\
\text { Norwegian }\end{array}$} \\
\hline & & & \multicolumn{2}{|c|}{ (Seconds/ PCU) } & & \\
\hline North & 2,400 & 45 & 40.76 & 39.53 & E & $\mathrm{D}$ \\
\hline South & 1,200 & - & 22.76 & 21.00 & $\mathrm{C}$ & $\mathrm{C}$ \\
\hline West & 2,100 & 25 & 31.60 & 27.70 & $\mathrm{D}$ & $\mathrm{D}$ \\
\hline
\end{tabular}

Note: Calculations do not include vehicles coming from the eastern section. 


\subsection{Factors that Affect Travel Delays}

This paper investigated when both the volume of the vehicle passing and its degree of saturation were constant. Its degree of saturation (DS) was about 0.5 . It meant that no remaining unfinished vehicle crossed the intersection when the green signal lighted upon a traffic light cycle.

Based on the results of the study above, the following are the dominant factors that affect travel delays in the above intersection. These factors are (1). The number of vehicles to turn left even though the traffic signal was red (LTOR), (2). The number of traffic lights phases, (3). The time interval of all red signals to clear the intersection of the flow of vehicle movement in different directions, and (4). The implementation of the modification of Norwegian traffic lights.

The number of vehicles those turn left even though the traffic signal is red (LTOR), they have a negative correlation. As their volume increase, the travel delays will decrease. The number of traffic lights phases has a positive correlation. The intersection which has many numbers of phases, the travel delay become higher. The travel delay at the intersection of four-phase traffic lights is higher than the intersection which implements three phases. However, it also depends on the time interval for the green signal in each phase. The time interval of all red signals has a positive correlation. For this massive size, intersection needs six seconds. The implication, the massive size of the intersection has a high travel delay. The modification of Norwegian traffic lights can reduce travel delays better than standard systems.

The reality, according to the experts' observation, the intersection can be categorized as having a medium LoS. However, this cannot be represented in the standard of travel delay measurement.

The best method to improve travel delays is to build a flyover. This is provided for the flow of vehicles coming from the eastern section and going to another section. This only needs to implement three phases. The duration of one traffic light cycle is 93 seconds. The average travel delays for vehicles originating from the south, north, and west sections are 39.53 seconds, 21.00 seconds, and 27.70 seconds, respectively. The Index of the Level of Services (LoS) are C, D, and D, respectively. If the volume of vehicle traffic flows to increase, the existence of the flyover cannot be delayed anymore.

\section{Conclusions}

Generally, the implementation of modifications of the Norwegian traffic signal system in both a small intersection and a low of traffic flow can reduce travel delays. However, when compared to standard system traffic signals in both a massive size of the intersection and a heavy traffic flow, the results are not significant. The reason, it has not succeeded in increasing the Level of Service (LoS) score. Refers to the experts of the transportation. It requires the higher LoS Index for the massive intersection. When the situation is urgent, and the traffic volume increases continuously, to improve the travel delay can be by building the flyover.

\section{Acknowledgements}

This research is funded by KEMENRISTEK DIKTI of Republic of Indonesia and UNMER Madiun in 2018.

\section{REFERENCES}

[1] Y. S. Huang, Y. S. Weng, and M. C. Zhou, Modular Design of Urban Traffic-Light Control Systems Based on Synchronized Timed Petri Nets, IEEE On Intelligent Transportation Systems, Vol. 15, No. 2, April 2014

[2] R. Kurniawan, and R. A. Al-Hasibi, The Concept of Adaptive Traffic Control that Synchronized with Density as Solutions to Minimize the Duration of the Waiting Time of Vehicles, Semesta Teknik, The Scientific Journal, Vol. 2., No. 10, Faculty of Engineering, UMY, 2007, pp. 126-135.

[3] O.Z. Tamin Transport Planning \& Modeling, ITB Publisher, Bandung, 2000.

[4] ICHM, Indonesian Capacity Highway Manual, Directorate of Highways Directorate of Road Development City, Jakarta, 1997.

[5] J. Kou, Reasoning Techniques Used For Data Processing, Master's Thesis, Faculty of Science and Technology, University of Stavanger, June 15th, 2010.

[6] R. Davidrajuh, Developing a Petri Nets based Real-Time Control Simulator, DOI 10.5013/IJSSST.a.13.02.04.

[7] D. Adzkiya, Modeling Traffic Light Using Petri Net and Its Simulation, Master's Thesis, Sepuluh Nopember Institute of Technology, unpublished, Surabaya, 2008.

[8] M. Soares, Architecture-Driven Integration of Modeling Languages for the Design of Software-Intensive Systems, The Thesis, Next Generation Infrastructures Foundation, Delft, Netherlands, February 2010, pp. 99-133.

[9] T. Murata, Petri Net: Properties, Analysis, and Applications, Proceedings of IEEE, 77, 1989, pp 541-590.

[10] C.G.Cassandras and S. Lafortune, Introduction to Discrete Event Systems, The International Series on Discrete Event Dynamic Systems, Kluwer Academic Publishers, Norwell, Massachusetts, USA, 1999.

[11] M. Dotolia and M.P. Fanti, Urban Traffic Network Model Via Colored Timed Petri Nets. Control Engineering Practice, 2006, Vol. 10, No. 14, pp. 1213-1229.

[12] M. B. Asih, and I. Muthohar, Efforts to Solve Traffic Problems due to High Sideroad Activity Using Delays Analysis, Upaya Pemecahan Masalah Lalu Lintas Akibat Aktivitas Sisi Jalan yang Tinggi dengan Analisis Tundaan, The 15th FSTPT International Symposium, STTD Bekasi, November 23-24, 2012. 
[13] A. Narendra and A. Budiwirawan, Study of Handling on Delay of Movement of An Intersection Banaran-Sekaran that Has Four Arm, Studi Penanganan Tundaan Pergerakan di Persimpangan Empat Banaran-Sekaran, Jurnal Teknik Sipil \& Perencanaan, Vol. 16, No. 1, Department of Civil Engineering, UNNES, January 2014, pp.: $1-14$

[14] F. Kurniawan, H. Sajati, and O. Dinaryanto, Adaptive Traffic Controller Based On Pre-Timed System, TELKOMNIKA, Journal of Telecommunication, Computing, Electronics, and control, Vol. 14, No. 1, March 2016
[15] M. Papageorgiou, C. Diakaki, V. Dinopoulou, A. Kotsialos, Y. Wang, Review of Road Traffic Control Strategies, Proceedings of IEEE, 2003, pp. 2043-2067.

[16] T. Tristono, Study of Traffic Vehicles Delay on A Signalized Intersection Integrated to The Railway Doorstop, Journal Agritek, Vol. 1, No. 15, University of Merdeka Madiun, March 2014, pp. 81-91. 